\title{
ESTILOS DE CRIANZA Y EMPATÍA EN ADOLESCENTES IMPLICADOS EN CIBERBULLYING
}

\author{
PARENTING STYLES AND EMPATHY IN ADOLESCENTS INVOLVED IN \\ CYBERBULLYING
}

\author{
Alberto Quintana*, William Montgomery, Carmela Malaver, Gabriela Ruiz, Nayú Garcia, Eduardo Moras. \\ Universidad Nacional Mayor de San Marcos, Lima, Perú \\ (RECIBIDO 20-08-2013, ACEPTADO 22-10-2013)
}

\begin{abstract}
RESUMEN
El presente estudio tuvo como finalidad analizar la relación entre los estilos de socialización parental, el proceso de empatía y el fenómeno del ciberbullying, cuyo ámbito se expande más allá de las fronteras físicas de la escuela, pudiéndose direccionar desde el hogar de los adolescentes a los escenarios digitales. Al respecto se investigó a los alumnos provenientes de instituciones educativas públicas y privadas de Lima Metropolitana obteniendo una muestra de 560 adolescentes de ambos sexos entre 13 y 17 años. A esta muestra se le administró la escala de estilos de socialización parental en la adolescencia (ESPA 29), que proporciona los estilos de socialización parental de la madre y el padre, el Interpersonal Reactivity Index (IRI), que mide el grado de Empatía y el Cuestionario de Ciberbullying de Calvete, (E., Orue, I., Estevez, A., Villardón, y Padilla, P., 2009), que mide tanto la realización de ciberbullying como hecho de ser víctima de ciberbullying. Se recogió la información mediante un diseño de tipo descriptivo-correlacional, con un muestreo por conglomerados de la población a estudiar. Se encontraron correlaciones entre los estilos de socialización parental y el grado de empatía; y entre el grado de empatía y la participación en episodios de ciberbullying, sea en el rol de víctima o en el de victimario, comprobándose tres de las cuatro hipótesis formuladas, a la vez que no se encontró correlaciones significativas entre los estilos de socialización parental y la participación en episodios de ciberbullying, rechazándose la cuarta hipótesis. Habiéndose logrado la mayor parte de los objetivos propuestos en esta investigación estos resultados coadyuvaran al desarrollo de un Protocolo de intervención en ciberbullying, que facilitará el desarrollo de estrategias de promoción de comportamientos prosociales en la población afectada.
\end{abstract}

Palabras clave: ciberbullying, estilos de crianza, empatía, adolescentes

\footnotetext{
* Docente Principal de la Facultad de Psicología de la UNMSM. E-mail: albertolqp@hotmail.com
} 


\begin{abstract}
He present study aimed to analyze the relationship between parental socialization styles, the process of empathy and the phenomenon of cyberbullying, the scope expands beyond the physical boundaries of the school, being able to route from home to teenagers to digital scenes. In this regard we investigated students from public and private educational institutions of Punjab obtaining a sample of 560 adolescents of both sexes between 13 and 17 years old. This sample was administered the scale of parental socialization styles in adolescence (ESPA 29) that provides parental socialization styles of mother and father, the Interpersonal Reactivity Index (IRI), which measures the degree of empathy and Questionnaire of Cyberbullying (Calvete, E., Orue, I., Estevez, A., Villardón, and Padilla, P., 2009) that measures both the realization of cyberbullying as being a victim of cyberbullying. The Information was collected through a design-correlational descriptive, with a cluster sampling of the study population. Correlations were found between parental socialization styles and degree of empathy, and between the degree of empathy and participation in episodes of cyberbullying, whether in the role of victim or perpetrator of and found three of the four hypotheses, to while no significant correlations were found between parental socialization styles and participation in episodes of cyberbullying, rejecting the fourth hypothesis. We are having achieved most of the objectives in this research these results will contribute to the development of an intervention protocol in cyberbullying, which will facilitate the development of strategies to promote prosocial behaviors in the affected population.
\end{abstract}

Keywords: cyberbullying, parenting Styles, empathy, adolescents

\title{
INTRODUCCIÓN
}

En estudios precedentes (Quintana, et al., 2009, 2010) investigamos alumnos espectadores de bullying a fin de conocer cómo su presencia afecta a la dinámica de este tipo de violencia, reconociéndose que el espectador es un actor fundamental en su incremento o ausencia, dependiendo del rol reforzante o sancionador que desempeñe. Sin embargo al abordar este fenómeno sistémico observamos que la violencia entre pares trasunta los linderos geográficos de la escuela y opera también en espacios digitales, adquiriendo "personería" en el ciberbullying que encuentra en la tecnología un aliado para su propagación, anonimato, diversificación y permanencia. Por lo cual continuando con nuestra línea de investigación sobre violencia en contextos educativos consideramos relevante abordar la temática del ciberbullying.

\section{Planteamiento del estudio}

Actualmente esta modalidad de bullying viene siendo estudiada por las repercusiones globalizadas, la prevalencia que va adquiriendo y su devastador efecto punitivo en la víctima (Ortega y cols., 2008; Avilés, 2009; García y cols., 2010), donde el acosador suele ser anónimo, y utiliza textos e imágenes cibernéticas enviadas desde fuentes remotas (correo electrónico, chat, Facebook, mensajes por celular, Twitter), y operativizadas desde sus hogares o utilizando las cabinas de Internet (hasta en un 70\% dice el Grupo Telefónica del Perú). Estas características multiplican e intensifican los efectos lesivos, punitivos del acoso por varias 
razones, entre las cuales se hallan: 1) la impotencia e indefensión que genera en las víctimas el anonimato del agresor, 2) la vergüenza que provoca el hecho de ser masivamente difundido, en el sentido de poder ser visto públicamente en la web, y 3) su posibilidad de ser visionado varias veces (García y cols., 2010). Al respecto, nuestra investigación pretende contrastar la información respecto a si la socialización parental familiar influye sobre el comportamiento de las personas implicadas en episodios de ciberbullying, entendiendo que el núcleo familiar representa la primera entidad formativa y referente para las autopercepciones de valía personal, desarrollo de principios, valores y conducta moral, constituyéndose los padres en eficaces modelos del uso de normas, refuerzos y castigos, mostrándole a los hijos cómo actuar y/o asumir la toma de sus propias decisiones.

Por ello nos propusimos los siguientes objetivos en este estudio:

Determinar si existen relaciones significativas entre los estilos de socialización parental y el grado de empatía en escolares adolescentes.

Determinar si existen relaciones significativas entre los estilos de socialización parental y el comportamiento de ciberbullying en la escuela que presentan los adolescentes.

Determinar si existen relaciones significativas entre el grado de empatía y el comportamiento de ciberbullying en la escuela que presentan los adolescentes.

Determinar si existen relaciones significativas entre el grado de empatía y el ser víctima de episodios de ciberbullying en la escuela que presentan los adolescentes.

Siendo la meta fundamental explorar la relación entre los estilos de socialización parental, el grado de empatía y el comportamiento de ciberbullying que presentan los adolescentes, a fin de comprender mejor este fenómeno para su afrontamiento y complementar los estudios realizados por nuestro equipo en esta línea de investigación.

La identificación de relaciones entre la participación en actos de ciberbullying, los grados de Empatía y los Estilos de socialización parental de adolescentes provenientes de las instituciones educativas investigadas, contribuirá al desarrollo de un Protocolo de intervención en ciberbullying, que a su vez facilitará la articulación o el auspicio de estrategias de promoción, prevención, de desarrollo de comportamiento prosocial en la población afectada. Proponer programas de intervención para el desarrollo una convivencia pacífica y tolerancia a la inclusión.

Promover en entidades formadoras el desarrollo de actividades de perfeccionamiento profesional en relación con el tema investigado.

\section{La crianza de los hijos y los Estilos de Socialización Parental}

Las conductas concretas de los padres en las relaciones con sus hijos pueden variar en sus formas, pero hay puntos de convergencia importantes entre los miembros de una misma comunidad y, en concreto, en la actuación de los padres. Asimismo, la socialización implica que se delimite si los comportamientos son o no adecuados, 
lo cual está en función de la valoración que hacen los padres de las normas sociales en sentido amplio. Pero, en última instancia,independientemente del contenido específico, el aspecto relacional que supone la responsabilidad de los padres ante los comportamientos de los hijos es una constante que trasciende a la diversidad de las normas sociales (Darling y Steinberg, 1993, en Musitu y García, 2001). Las pautas de comportamiento de los padres con los hijos en múltiples y diferentes situaciones, permiten definir un estilo de actuación de los padres que podríamos denominar estilo de socialización. Los estilos de socialización parental se definen por la persistencia de ciertos patrones de actuación y las consecuencias que esos patrones tienen para la propia relación paterno-filial y para los miembros implicados. Si el hijo se comporta conforme a las normas familiares, la expectativa de este será que sus padres reconozcan su comportamiento expresando su complacencia y reconocimiento; en caso contrario, el hijo interpretará que los padres actúan con indiferencia. Si consideramos que ante la misma actuación significativa del hijo las respuestas de aprobación no son compatibles con las de indiferencia, puesto que es imposible que se produzcan simultáneamente las dos en un mismo tiempo y espacio, entonces, cuando el hijo se comporte de acuerdo con las normas, se podría valorar este comportamiento situándolo entre los dos extremos de la dimensión implicación/aceptación: la aceptación o el cariño parental en un extremo, y la indiferencia en el otro. El estilo de los padres de implicación/aceptación como una forma de actuación parental que se refleja tanto en las situaciones convergentes como divergentes con las normas de funcionamiento familiar. Se relaciona positivamente con las muestras parentales de afecto y cariño cuando el hijo se comporta de manera adecuada y, negativamente, con la indiferencia paterna ante esas mismas conductas. A su vez, cuando el comportamiento del hijo viola las normas, este estilo se relacionará positivamente con el diálogo y, negativamente, con la displicencia. Si el estilo de los padres se caracteriza por una alta implicación/aceptación, los hijos perciben que sus conductas acordes con la norma son estimadas por sus padres, mientras que cuando no lo son, los padres utilizan, predominantemente, el razonamiento y el diálogo. Por el contrario, si el estilo de los padres se caracteriza como de baja implicación/aceptación, actuarán con indiferencia cuando los hijos se comporten de acuerdo con las normas, y actuarán de forma displicente cuando las quebranten. Por otro lado, la coerción/imposición es un estilo de socialización que solo puede tener lugar cuando el comportamiento del hijo se considere discrepante con las normas de funcionamiento familiar. Esta forma de actuación pretende, normalmente, suprimir las conductas inadecuadas utilizando simultánea o independientemente la privación, la coerción verbal y la física. Estas estrategias que, aparentemente, suelen ser más efectivas que el diálogo y la comunicación, implican intervenciones drásticas con gran contenido emocional que pueden generar resentimiento en los hijos hacia los padres, problemas de conducta, de personalidad, etc., especialmente cuando se utiliza el castigo físico. Por otra parte, estas intervenciones, por su alta carga emocional pueden conseguir un control de la conducta inmediato, pero si no se acompañan del razonamiento y del diálogo, el control será temporal o estará limitado a la presencia del padre, que actuará como estímulo inhibidor. 
Al confluir las dos dimensiones los estilos de socialización de los padres pueden tipificarse en cuatro categorías, cada una de las cuales es caracterizada por una forma peculiar de afrontar la socialización de los hijos (Figura 1). (1) Estilo Autorizativo. Alta Aceptación/implicación y alta Coerción/imposición, son aquellos padres que se esfuerzan en dirigir las actividades del hijo pero de una manera racional y orientada al proceso; estimulan el diálogo verbal y comparten con el hijo el razonamiento que subyace a su política; valoran tanto los atributos expresivos como los instrumentales, las decisiones autónomas y la conformidad disciplinada. En consecuencia, ejercen el control firme en puntos de divergencia, pero utilizando el diálogo. Estos padres afirman las cualidades presentes del hijo, pero también establecen líneas para la conducta futura, recurriendo tanto a la razón como al poder para lograr sus objetivos.

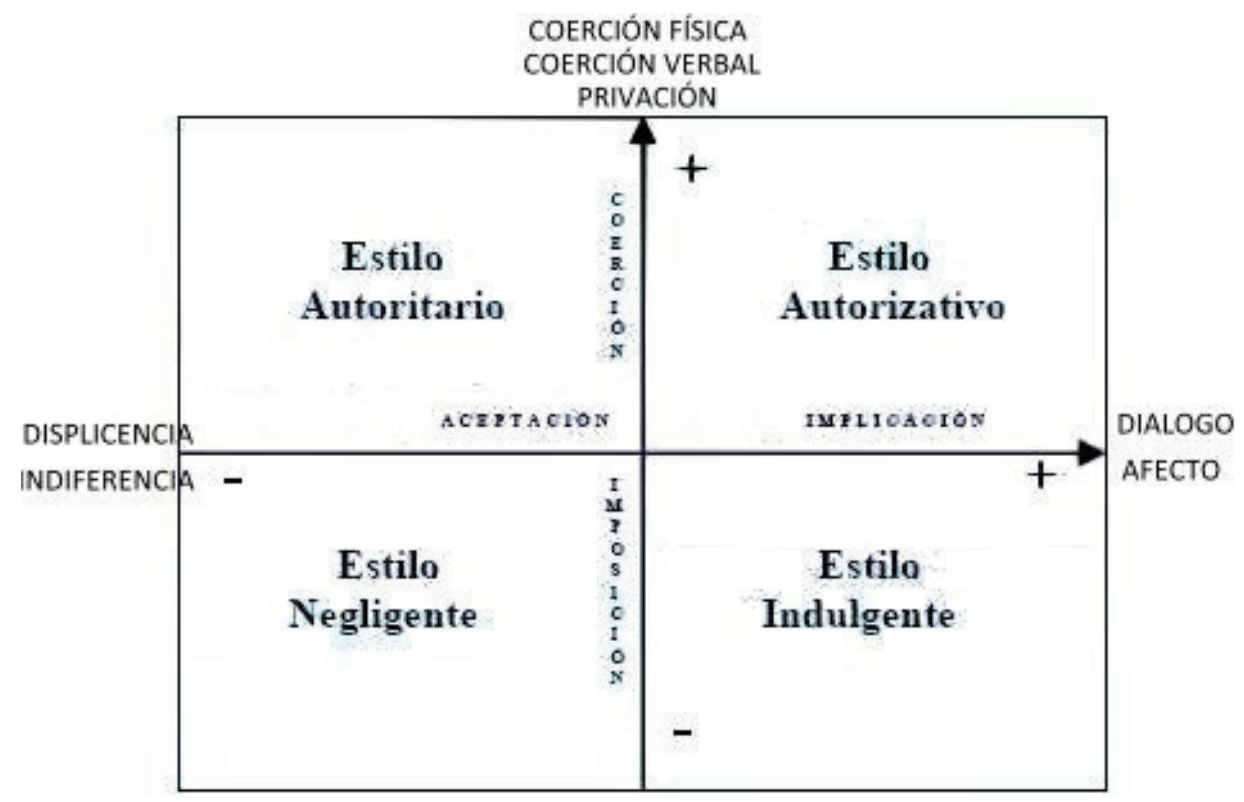

Fuente: Musitu y Garcia (2001).

Figura 1. Modelo bidimensional de socialización y tipologías

(2) Estilo indulgente; Alta Aceptación/implicación y baja Coerción/imposición. Estos padres intentan comportarse de una manera afectiva, aceptando los impulsos, deseos y acciones del hijo. Consultan con ellos las decisiones internas del hogar y les proporciona explicaciones de las reglas familiares. Permiten a sus hijos regular sus propias actividades tanto como sea posible, ayudándoles con las explicaciones y razonamientos, pero evita el ejercicio del control impositivo y coercitivo, y no les obliga a obedecer ciegamente a pautas impuestas por las figuras de autoridad, a no ser que estas sean razonadas. (3) Estilo Autoritario. Baja Aceptación/implicación y alta Coerción/imposición. Son los padres que intentan: modelar, controlar y 
evaluar la conducta y actitudes del hijo de acuerdo con un conjunto de normas de conducta, normalmente de forma absoluta. Valoran la obediencia como una virtud y favorecen medidas punitivas y de fuerza para doblegar la voluntad (la terquedad) cuando las acciones del hijo o las creencias personales de ese entran en conflicto con lo que ellos piensan que es una conducta correcta. Confían en la inculcación de valores instrumentales como el respeto por la autoridad, respeto por el trabajo y respeto por la preservación del orden y de la estructura tradicional. No potencian el diálogo verbal, y creen que el hijo debería aceptar solamente su palabra que es la "absolutamente" correcta. (4) Estilo negligente; baja Aceptación/implicación y baja Coerción/imposición. Aquellos padres que tienen serias dificultades para relacionarse e interactuar con sus hijos, al igual que para definir los límites en sus relaciones con ellos, permitiendo con indefensión que sean los propios hijos quienes las definan; aceptan con dificultades los cambios evolutivos de sus hijos y tienen pocas expresiones de afecto; no se implican en las interacciones con ellos y no supervisan constante y consistentemente las actividades de los hijos.

\section{La Empatía}

La respuesta empática incluye la capacidad para comprender al otro y ponerse en su lugar, a partir de lo que se observa, de la información verbal o de información accesible desde la memoria (toma de perspectiva) y además la reacción afectiva de compartir su estado emocional, que puede producir tristeza, malestar o ansiedad. Davis (1983) considera a la empatía como un constructo multidimensional que incluye componentes cognitivos y emocionales y cree que en realidad constituye un conjunto de constructos relacionados con la sensibilidad hacia los otros. Basándose en este modelo desarrolló el Interpersonal Reactivity Index (IRI) (Davis, 1980). El cual consta de cuatro factores dos cognitivos y dos emocionales: Toma de perspectiva (PT), tendencia o habilidad de los sujetos para adoptar la perspectiva o punto de vista de otras personas; Fantasía (FS), la tendencia de los sujetos a identificarse con personajes ficticios como personajes de libros y películas; Preocupación empática (EC), tendencia de los sujetos a experimentar sentimientos de compasión y preocupación hacia otros; Malestar personal (PD), tendencia de los sujetos a experimentar sentimientos de incomodidad y ansiedad cuando son testigos de experiencias negativas de otros.

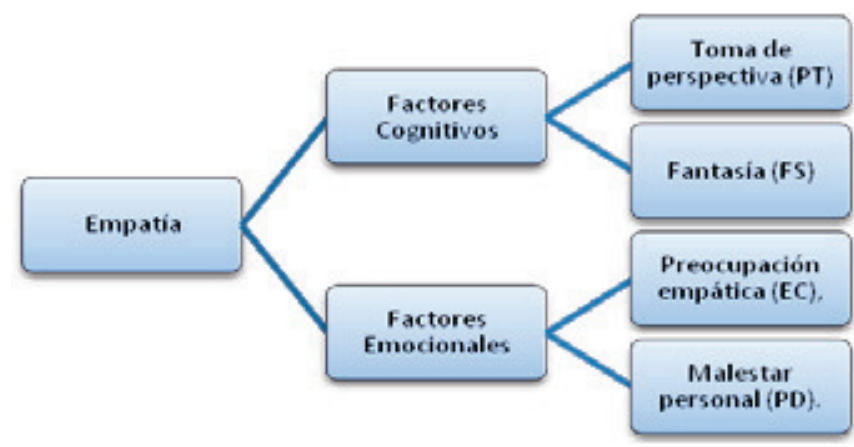

Figura 2. Factores cognitivos y emocionales de la empatía. 
Por ello, es muy importante verificar el tipo de disciplina y prácticas de socialización parental predominantes en el hogar, ya que la efectividad disciplinaria paterna se liga al método particular de socialización parental utilizado (Samper, 1999; Samper y cols., 2006). Visualizándose con el estudio de Mestre (2007) que la expresión de reconocimiento, gratitud, evaluación positiva por parte de los padres hacia sus hijos, así como también de apoyo emocional, estimulación en el desarrollo de su autonomía y coherencia en la aplicación de normas resulta ser el estilo de socialización parental más positivo, incentivando la respuesta empática en sus hijos, como refiere Valiente (2004, citado por Mestre, 2007), entendida cognitivamente como un proceso que involucra la habilidad para reconocer e interpretar sentimientos, pensamientos y puntos de vista ajenos, facilitando la comprensión de sus motivaciones, de sus sentimientos hacia ellos, siendo mediadora para la disminución de conductas agresivas y desarrollo de conductas prosociales o altruistas.

\section{Ciberbullying, Tipos}

En sentido estricto hablar del ciberbullying y el acoso cibernético no es hablar de nuevos temas, sino más bien de las nuevas herramientas que se utilizan. Es decir, estamos hablando del acoso entre pares o bullying, por ello es necesario explicitar los nuevos escenarios que contextualizan esta forma de violencia entre pares. Motivados por el desarrollo de las nuevas tecnologías y su accesibilidad a la población general, han surgido contextos y escenarios de relación interpersonal virtual: Hotmail, Hi5, Facebook, Messenger, Twitter, entre otros. La aparición de estos nuevos escenarios de interacción con sus iguales les brinda la oportunidad a los escolares de poner en juego, en un nuevo espacio, los mismos patrones de interacción que están presentes en las relaciones que mantienen con sus iguales en otros contextos de interacción (Castells, 1999), lo que supondría por tanto que las manifestaciones de violencia entre iguales sean adaptadas ahora a las particularidades propias de este nuevo medio. Por ello no resulta extraño que la presencia de un patrón de interacción de abuso, dominio-sumisión o violencia entre pares que se hace presente en las interacciones que se establecen entre los adolescentes y jóvenes, termine exportándose a los otros espacios o relaciones donde los adolescentes participan. El ciberbullying, es la conducta agresiva e intencional que se repite de forma frecuente en el tiempo, que se lleva a cabo por un grupo o un individuo mediante el uso de medios electrónicos, y se dirige a una víctima que no puede defenderse fácilmente por sí misma (Smith, Mahdavi, Carvalho y Tippet, 2006). Es decir, el ciberbullying no es otra cosa que el bullying utilizando las TIC (Internet: correo electrónico, weblogs, páginas personales, etc,; telefonía móvil). Kowalski, Limber y Agatston (2010) identifican ocho tipos de acoso cibernético: 1. Insultos electrónicos (PO), Peleas online o flaming: intercambio breve y acalorado entre dos o más personas con un lenguaje hostil y vulgar, que tiene lugar a través de alguna de las nuevas tecnologías. Intercambio de e-mails privados o intercambio en contextos públicos como chats... Intercambio mutuo de insultos entre varias personas implicadas. 2. Hostigamiento: mensajes ofensivos reiterados enviados a la persona elegida como blanco por correo electrónico, en foros públicos como salas de chat y foros de debate; envío de cientos o miles de mensajes de 
texto al teléfono móvil de la persona elegida como blanco. Difiere de los insultos porque el hostigamiento es más a largo plazo, es más unilateral (incluyendo a uno o más ofensores frente a una única víctima). 3. Denigración (D): modalidad que implica descalificar a alguien online difundiendo información despectiva y falsa respecto a la persona que es colgada en una página web o difundida vía e-mails, mensajes instantáneos..., por ejemplo, mediante el envío de imágenes crueles o rumores acerca de una persona para dañar su reputación o relaciones con amigos, de fotos de alguien alteradas digitalmente, sobre todo de forma que refleje actitudes sexuales o que puedan perjudicar a la persona en cuestión (foto alterada para que parezca que una adolescente está embarazada, comentarios maliciosos que se escriben en un "cuaderno de opiniones" online en el que se insinúa que una adolescente es sexualmente promiscua...). 4. Suplantación (S): infiltración en la cuenta de alguien para enviar mensajes que hacen quedar mal a su propietario, le ponen en situación problemática o en peligro, o dañan su reputación y amistades, por ejemplo, el acosador se hace pasar por la víctima, la mayoría de las veces utilizando la clave de acceso de la víctima para acceder a sus cuentas online y, a continuación, enviando mensajes negativos, agresivos o crueles a otras personas como si hubieran sido enviados por la propia víctima. 5. Desvelamiento y sonsacamiento (R) o Revelación: Difamación mediante la divulgación de secretos o información embarazosa de alguien, por ejemplo, implica revelar información comprometida de la víctima a otras personas, enviada de forma espontánea pero privada por la víctima o que ha sido sonsacada a la víctima y después difundida a otras personas. 6. Exclusión (E): no dejar participar a la persona de una red social o de un grupo on line específica. 7. Ciberpersecución o ciberacoso (CA): envío de comunicaciones electrónicas reiteradas hostigadoras y amenazantes. 8. Paliza alegre (Happy Slapping) (PA): consiste en grabar mediante la cámara de los teléfonos móviles imágenes en las que se agrede a una persona, frecuentemente en situación de minoría. La imagen o el video luego es compartido con amigos, colocado en algún espacio online o distribuido electrónicamente para que la vean miles de personas.

Recapitulando, con esta investigación se busca complementar los estudios que venimos realizando sobre acoso escolar entre pares, a fin de conformar un modelo funcional-integral que tenga en cuenta tanto los antecedentes como las consecuencias potenciales del bullying y ciberbullying, tal como se da en nuestro país. La investigación también aportará datos sobre la fiabilidad y validez de las pruebas utilizadas.

La exploración de la violencia entre pares, sus manifestaciones y los antecedentes y consecuencias que controlan este tipo de comportamiento son cada vez más numerosas, dado el alcance de los efectos negativos que tiene sobre los aspectos afectivos y cognitivos de la conducta escolar. En este contexto, el ciberbullying se constituye como una de las modalidades que más daño potencial representa, por su carácter expansivo, anónimo, diversificante y continuo en el escenario que le brinda los recursos de la tecnología de la información y comunicación (TIC), por ello se requiere recopilar, generar, analizar y sistematizar información acerca de sus características, dinámica, factores intervinientes, incidencia en nuestro país, y así contribuir al afrontamiento y control del fenómeno de la violencia escolar. 


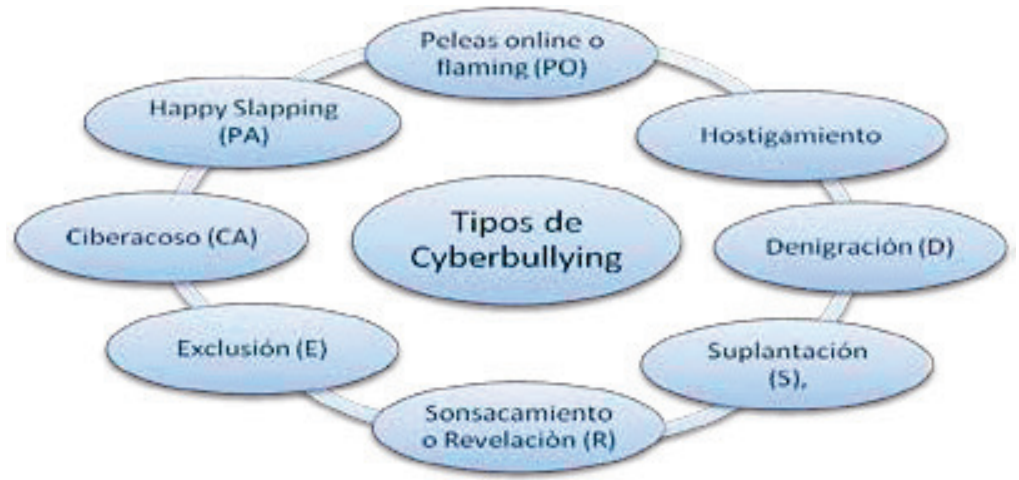

Figura 3. Tipos de ciberbullying, según Kowalski, Limber y Agatston (2010).

\section{Hipótesis}

1. Existen relaciones significativas entre los estilos de socialización parental y el grado de empatía en escolares adolescentes.

2. Existen relaciones significativas entre los estilos de socialización parental y el comportamiento de ciberbullying en la escuela que presentan los adolescentes.

3. Existen relaciones significativas entre el grado de empatía y el comportamiento de ciberbullying en la escuela que presentan los adolescentes.

4. Existen relaciones significativas entre el grado de empatía y el ser víctima de ciberbullying en la escuela que presentan los adolescentes.

\section{MÉTODO}

El diseño es de investigación básica descriptivo-correlacional y de tipo transversal.

La muestra está conformada por adolescentes provenientes de diversos centros educativos de Lima.

\section{Variables del estudio}

\section{Variable 1: Ciberbullying en el contexto escolar.}

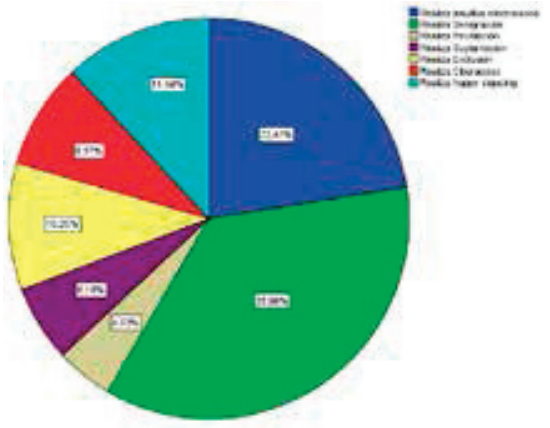

Figura 4. Distribución de los tipos de ciberbullying en la muestra 
EstiLOS DE CRIANZA Y EMPATIA EN ADOLESCENTES IMPLICADOS EN CIBERBULLYING

\section{Variable 2: Empatía en adolescentes.}

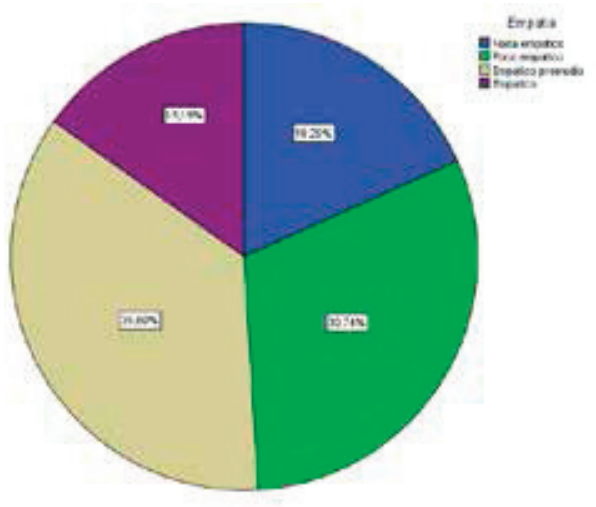

Figura 5. Distribución de los niveles de empatía en la muestra.

Variable 3: Estilos de socialización parental (crianza)

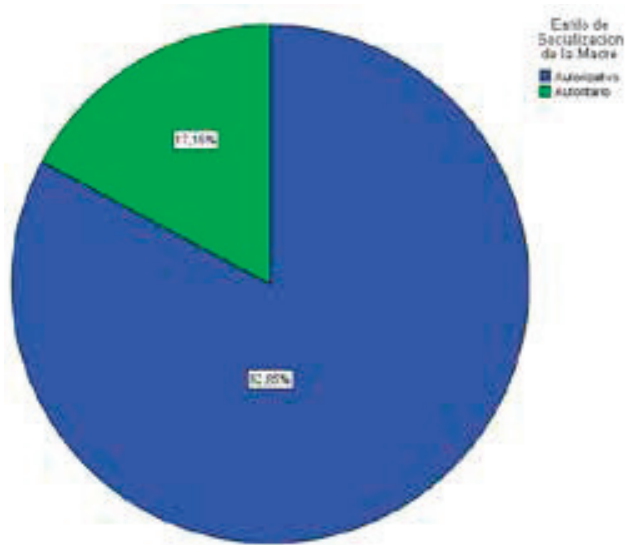

Figura 6. Distribución de los estilos de socializacion parental de la madre en la muestra.

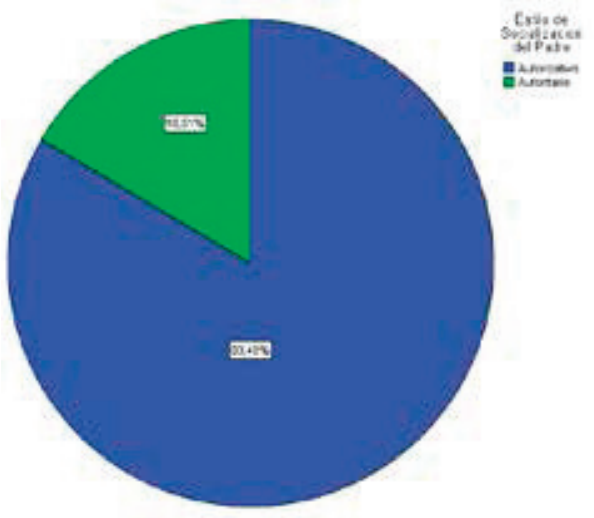

Figura 7. Distribución de los estilos de socialización parental del padre en la muestra. 


\section{Variables controladas:}

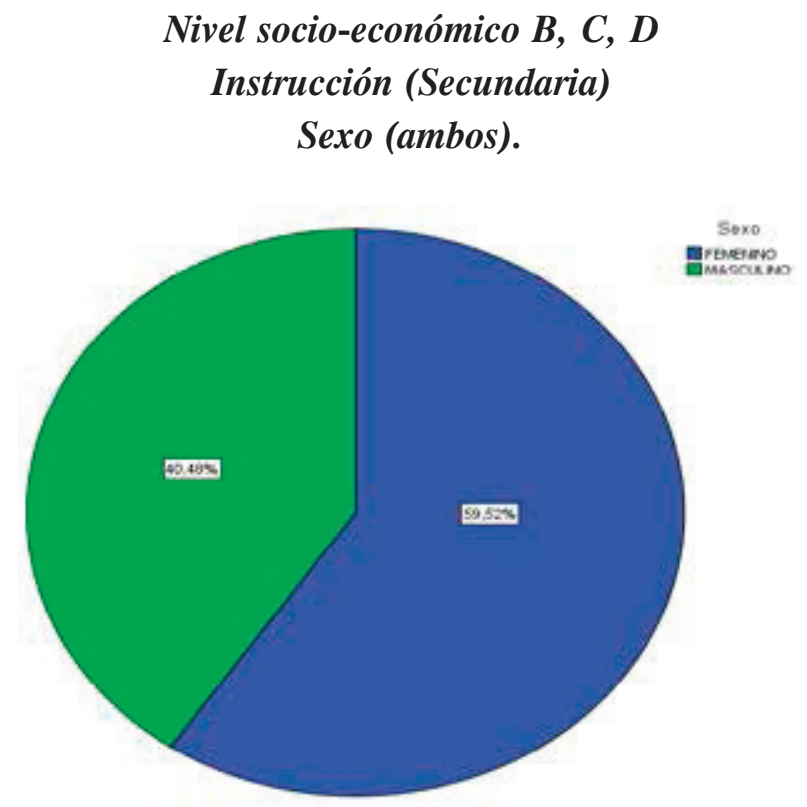

Figura 8. Distribución de los sujetos de la muestra en función del sexo

Área geográfica (Lima Metropolitana).

\section{Técnicas e instrumentos de recolección de datos}

1. Ficha demográfica: Permite registrar algunas características relevantes de los sujetos estudiados: lugar de residencia, edad, sexo, grado de instrucción, etc.

2. Cuestionario de ciberbullying de Calvete, E., Orue, I., Estevez, A., Villardón, y Padilla, P. (2009), tanto la versión para la víctima que cuenta con 11 reactivos en las que el adolescente debe marcar la frecuencia con la que ha recibido maltrato virtual, como la versión para el abusador que cuenta con 17 reactivos en las que el adolescente debe marcar la frecuencia con la que ha enviado agresiones virtuales. De los ocho tipos de acoso cibernético identificados por Kowalski, Limber y Agatston (2010), este instrumento permite identificar los siguientes: Insultos electrónicos, Peleas online o flaming (PO), Denigración (D), Suplantación (S), Desvelamiento y sonsacamiento o revelación (R), Exclusión (E), ciberpersecución (CA) o ciberacoso, y paliza alegre o Happy Slapping (PA).

3. Interpersonal Reactivity Index, IRI (Davis, 1983). Esta prueba consta de 28 ítems con un formato de respuesta tipo Likert con cinco opciones de respuesta, puntuables de $0 \mathrm{a}$ 4 y permite evaluar la disposición empática a través de cuatro factores, dos cognitivos: Toma de perspectiva (PT) y Fantasía (FS), y dos emocionales, la Preocupación empática (EC), y el Malestar personal (PD). Los coeficientes de consistencia interna varían entre 0.70 y 0.78 (Pérez - Abéniz y cols., 2003). 
4. Escala de Estilos de Socialización Parental en la Adolescencia (ESPA29), de Musitu y García (2001). Es un instrumento que permite al adolescente valorar la actuación de su padre y madre en 29 situaciones significativas obteniendo una medida global para cada figura parental en las dimensiones a) Aceptación / Implicación; que comprende las subescalas: afecto, indiferencia, diálogo e indiferencia y b) Coerción / Imposición constituida por las subescalas: coerción física, privación y coerción verbal; A partir de las puntuaciones alcanzadas en estas dos dimensiones, se tipifica el estilo de socialización de cada padre : autorizativo, indulgente, autoritario o negligente. Los autores reportan las estimaciones de fiabilidad: La consistencia interna del conjunto global de la escala es de 0,968 según alfa de Cronbach. Madre: afecto 0,943; indiferencia 0,918; diálogo 0,930; displicencia 0,840 ; coerción verbal 0,897 ; coerción física 0,901 y privación 0,913. Padre: afecto 0,940 ; indiferencia 0,922 ; diálogo 0,931 ; displicencia 0,820 ; coerción verbal 0,901; coerción física 0,907 y privación 0,916 . Y de Validez: Los hijos y las hijas percibían que la acción socializadora del padre respecto de la madre, se caracterizaba por un grado mayor de Aceptación/Implicación. No existen diferencias entre las edades (Musitu y García, 2001).

\section{DISCUSIÓN}

Se presentan y discuten los resultados resumidos mediante gráficas y tablas organizados en relación a las hipótesis sometidas a contrastación.

\section{Existen relaciones significativas entre los estilos de socialización parental y la empatía en adolescentes escolares}

En consonancia con lo que se postulaba en la primera hipótesis existe una correlación directa y significativa, entre el grado de empatía que muestran los adolescentes y los estilos de socialización parental que perciben en su entorno familiar.

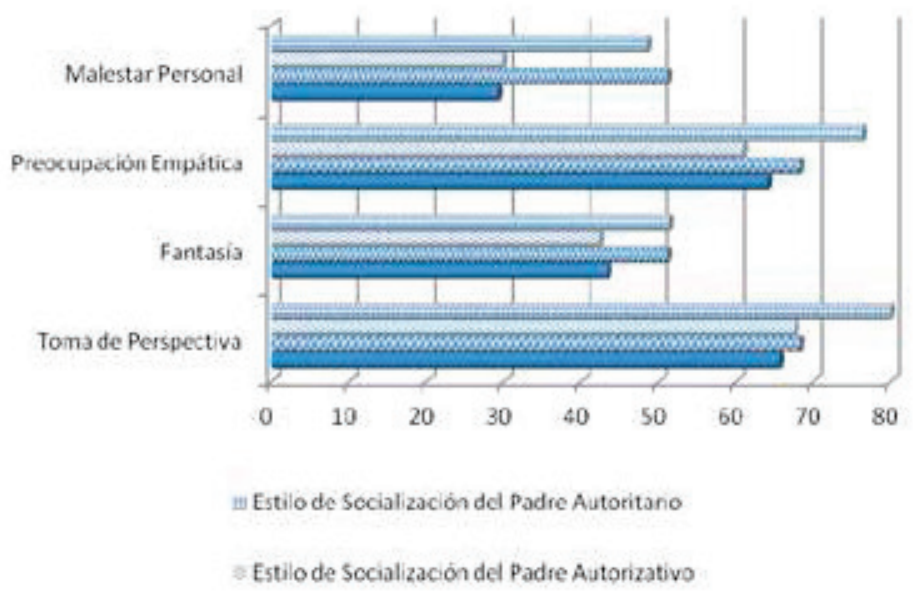

Figura 9. Componentes de la autoestima según los estilos de socialización de ambos padres. 
Tabla 1. Correlación entre los estilos de socialización parental con la empatía y sus componentes en la muestra estudiada

\begin{tabular}{llrr}
\hline \multirow{2}{*}{ Estilo de Socialización de la Madre } & \multicolumn{2}{c}{ Tau_b de Kendall } \\
& & $\begin{array}{c}\text { Estilo de Socialización } \\
\text { del Padre }\end{array}$ \\
\hline \multirow{3}{*}{ Empatía } & Coeficiente de correlación &, 084 &, $164^{* *}$ \\
& Sig. (bilateral) &, 116 &, 004 \\
& $N$ & 559 & 552 \\
\hline \multirow{2}{*}{ Toma de perspectiva } & Coeficiente de correlación &,- 001 &, $142^{*}$ \\
empática & Sig. (bilateral) &, 986 &, 014 \\
& $\mathrm{~N}$ & 559 & 552 \\
\hline \multirow{3}{*}{ Identificación con } & Coeficiente de correlación &, 035 &, 067 \\
personajes o Fantasía & Sig. (bilateral) &, 513 &, 247 \\
& $\mathrm{~N}$ & 559 & 552 \\
\hline \multirow{3}{*}{ Preocupación empática } & Coeficiente de correlación &, 044 &, $136^{*}$ \\
& Sig. (bilateral) &, 421 &, 019 \\
& $\mathrm{~N}$ & 559 & 552 \\
\hline \multirow{3}{*}{ Malestarpersonal } & Coeficiente de correlación &, $144^{* *}$ &, $124^{*}$ \\
& Sig. (bilateral) &, 008 &, 032 \\
& $N$ & 559 & 552 \\
\hline
\end{tabular}

** La correlación es significativa al nivel 0,01 (bilateral).

* La correlación es significativa al nivel 0,05 (bilateral).

Específicamente, se puede observar en la Tabla 1 y Figura 9, el grado de asociación altamente significativo entre la empatía y el Estilo de Socialización del Padre (.164), asociación que se presenta también entre el Estilo de Socialización del Padre y los componentes Toma de perspectiva empática (.142), Preocupación empática (.136) y Malestar personal (.124) de la empatía. De otro lado, si bien no se encuentra una correlación significativa entre el grado de empatía que muestran los adolescentes y Estilo de Socialización Parental que perciben en la madre, sin embargo, si se encuentra una correlación directa y altamente significativa, entre el estilo de socialización parental de la madre y el componente Malestar personal de la empatía (.144). Concretamente, como se observa en la Figura 9, los adolescentes que perciben en sus padres un estilo de socialización parental autorizativo van a tender a presentar menos empatía que los adolescentes que perciben en sus padres un estilo de socialización parental autoritario, sobre todo si quien presenta este estilo de socialización es el padre, a excepción del componente Identificación con personajes o Fantasía, de la empatía, posiblemente porque este componente implica menos compromiso emocional que los otros componentes (Davis, M, 1983). Esto tendría que ver con el hecho de que en la práctica aún se le asigna al padre la función de ejercer el control y la disciplina en las familias limeñas (Oblitas B; 2009). 
Existen relaciones significativas entre los estilos de socialización parental y el comportamiento de ciberbullying en la escuela que presentan los adolescentes

En cuanto a la segunda hipótesis formulada en este estudio, no se corroboró ninguna correlación ni con la variable total ni con sus componentes que resultara significativa, es decir, no se aprecia correlación alguna entre el estilo de socialización parental familiar y la práctica del ciberbullying en los adolescentes estudiados. Resultado perfectamente explicable por el hecho de que los jóvenes se están adaptando a una cultura nueva regida por la tecnología y que se impone al modo de vida de baja tecnología de sus padres (García, F. 2010), el adolescente sería probablemente más suceptible de ser influenciado por sus pares, de hecho más competentes en estos escenarios y en consecuencia modelos más adecuados para imitar (Bandura y Walters, 1978).

Existen relaciones significativas entre el grado de empatía y el comportamiento de ciberbullying que presentan los adolescentes escolares

En consonancia, con lo que se postulaba en la tercera hipótesis existe una correlación inversa y significativa, entre el grado de empatía que muestran los adolescentes y el dedicarse a hacer ciberbullying a sus compañeros $(-, 119)$, y así mismo, entre los componentes de la empatía y los tipos de ciberbullying evaluados en el presente estudio, a saber: existe una correlación inversa y significativa entre la empatía y enfrascarse en actividades de Denigración $(-, 105)$, Suplantación $(-, 160)$, Ciberacoso $(-, 135)$ o de Happy Slapping $(-, 116)$ contra sus compañeros.

Tabla 2.- Correlación entre los tipos de ciberbullying y la empatía en la muestra estudiada

\begin{tabular}{|c|c|c|c|c|c|c|}
\hline \multicolumn{7}{|c|}{ Tau_b de Kendall } \\
\hline \multicolumn{2}{|c|}{ Empatía } & \multirow{2}{*}{$\begin{array}{r}\begin{array}{c}\text { Toma de } \\
\text { perspectiva } \\
\text { empática }\end{array} \\
-, 119^{* *}\end{array}$} & \multirow{2}{*}{$\begin{array}{c}\begin{array}{c}\text { Identificación } \\
\text { con } \\
\text { personajes }\end{array} \\
-, 141^{* *}\end{array}$} & \multirow{2}{*}{$\begin{array}{r}\text { Preocupación } \\
\text { empática }\end{array}$} & \multicolumn{2}{|l|}{ Malestar } \\
\hline \multirow{3}{*}{ Ciberbullying } & $\begin{array}{l}\text { Coeficiente de } \\
\text { correlación }\end{array}$ & & & &,$- 092^{*}$ &,- 057 \\
\hline & Sig. (bilateral) & ,008 & ,002 & ,095 &, 046 & ,218 \\
\hline & $\mathrm{N}$ & 560 & 560 & 560 & 560 & 560 \\
\hline \multirow{3}{*}{$\begin{array}{l}\text { Realiza } \\
\text { insultos } \\
\text { electrónicos }\end{array}$} & $\begin{array}{l}\text { Coeficiente de } \\
\text { correlación }\end{array}$ &,- 059 &,$- 130^{*}$ &,- 040 &,- 043 & ,020 \\
\hline & Sig. (bilateral) & ,240 & ,011 & ,432 & ,404 & ,689 \\
\hline & $\mathrm{N}$ & 560 & 560 & 560 & 560 & 560 \\
\hline \multirow{3}{*}{$\begin{array}{l}\text { Realiza } \\
\text { Denigración }\end{array}$} & $\begin{array}{l}\text { Coeficiente de } \\
\text { correlación }\end{array}$ &,$- 105^{*}$ &,$- 115^{*}$ &,- 060 &,$- 102^{*}$ &,- 043 \\
\hline & Sig. (bilateral) & ,028 & ,018 & ,217 & ,035 & ,374 \\
\hline & $\mathrm{N}$ & 560 & 560 & 560 & 560 & 560 \\
\hline
\end{tabular}


Alberto Quintana, William Montgomery, Carmela Malaver, Gabriela Ruiz, Nayú García, Eduardo Moras

\begin{tabular}{|c|c|c|c|c|c|c|}
\hline \multirow{3}{*}{$\begin{array}{l}\text { Realiza } \\
\text { Revelación }\end{array}$} & $\begin{array}{l}\text { Coeficiente de } \\
\text { correlación }\end{array}$ & ,007 &,- 042 &, 013 & ,033 &,- 012 \\
\hline & Sig. (bilateral) & ,898 & ,429 & ,804 & ,536 & 825 \\
\hline & $\mathrm{N}$ & 560 & 560 & 560 & 560 & 560 \\
\hline \multirow{3}{*}{$\begin{array}{l}\text { Realiza } \\
\text { suplantación }\end{array}$} & $\begin{array}{l}\text { Coeficiente de } \\
\text { correlación }\end{array}$ &,$- 160^{* *}$ &,- 100 &,- 094 &,- 081 &,$- 131^{*}$ \\
\hline & Sig. (bilateral) & ,002 & ,055 & ,071 & 123 &, 012 \\
\hline & $\mathrm{N}$ & 560 & 560 & 560 & 560 & 560 \\
\hline \multirow{3}{*}{$\begin{array}{l}\text { Realiza } \\
\text { exclusión }\end{array}$} & $\begin{array}{l}\text { Coeficiente de } \\
\text { correlación }\end{array}$ &,- 095 &,$- 116^{*}$ &,- 014 &,- 065 &,- 066 \\
\hline & Sig. (bilateral) & ,064 & ,026 & ,783 & ,210 & ,207 \\
\hline & $\mathrm{N}$ & 560 & 560 & 560 & 560 & 560 \\
\hline \multirow{3}{*}{$\begin{array}{l}\text { Realiza } \\
\text { ciberacoso }\end{array}$} & $\begin{array}{l}\text { Coeficiente de } \\
\text { correlación }\end{array}$ &,$- 135^{* *}$ &,$- 128^{*}$ &,- 080 &,- 069 &,$- 103^{*}$ \\
\hline & Sig. (bilateral) & ,008 & ,013 & ,121 & 180 & ,046 \\
\hline & $\mathrm{N}$ & 560 & 560 & 560 & 560 & 560 \\
\hline \multirow{3}{*}{$\begin{array}{l}\text { Realiza } \\
\text { Happy } \\
\text { Slapping }\end{array}$} & $\begin{array}{l}\text { Coeficiente de } \\
\text { correlación }\end{array}$ &,$- 116^{*}$ &,$- 105^{*}$ &,- 049 &,$- 117^{\star}$ &,- 071 \\
\hline & Sig. (bilateral) & ,021 & ,040 & ,339 & ,023 & 165 \\
\hline & $\mathrm{N}$ & 560 & 560 & 560 & 560 & 560 \\
\hline
\end{tabular}

De igual forma, existe una correlación inversa y significativa entre el componente de la empatía de Toma de perspectiva empática y enfrascarse en actividades de Cyberbullying en general $(-, 141)$ o en el de alguno de sus tipos, como realizar Insultos electrónicos $(-, 130)$, la Denigración $(-, 115)$, la Exclusión $(-, 116)$, el Ciberacoso $(-, 128)$ o el Happy Slapping $(-, 105)$. En el mismo sentido, existe una correlación inversa y significativa entre el componente de la empatía de Preocupación empática y enfrascarse en actividades de Cyberbullying en general $(-, 092)$ o en el de alguno de sus tipos, como realizar Denigración $(-, 102)$ o realizar Happy Slapping $(-, 117)$. Por último, existe una correlación inversa y significativa entre el componente de la empatía del Malestar personal y dedicarse a actividades de cyberbullying del tipo hacer Suplantación $(-, 131)$ o hacer Ciberacoso $(-, 103)$. Coincidiendo con los hallazgos de otros investigadores acerca de la violencia entre pares (Kowalski y Limber, 2007; Ortega, Calmaestra y Mora Merchán, 2008; Ortega, Sánchez y Menesini, 2002; citados por Garaigordobil, M., 2011) 
ESTILOS DE CRIANZA Y EMPATÍA EN ADOLESCENTES IMPLICADOS EN CIBERBULLYING

\section{Existen relaciones significativas entre el grado de empatía y el ser víctima de ciberbullying en los adolescentes escolares}

Tabla 3. Correlación entre los tipos de victimización por ciberbullying y la empatía en la muestra estudiada

\begin{tabular}{|c|c|c|c|c|c|c|}
\hline \multirow{2}{*}{\multicolumn{2}{|c|}{ Empatía }} & \multicolumn{5}{|c|}{ Tau_b de Kendall } \\
\hline & & $\begin{array}{l}\text { Toma de } \\
\text { perspectiva } \\
\text { empática }\end{array}$ & $\begin{array}{c}\text { Identificación } \\
\text { con } \\
\text { personajes }\end{array}$ & $\begin{array}{c}\text { Preocupación } \\
\text { empática }\end{array}$ & $\begin{array}{l}\text { Malestar } \\
\text { personal }\end{array}$ & \\
\hline \multirow{3}{*}{$\begin{array}{l}\text { Víctima de } \\
\text { ciberbullying }\end{array}$} & $\begin{array}{l}\text { Coeficiente de } \\
\text { correlación }\end{array}$ &,- 024 &,$- 108^{*}$ &, 009 & ,024 &,- 017 \\
\hline & Sig. (bilateral) & ,611 & ,024 & ,845 & ,611 & ,728 \\
\hline & $\mathrm{N}$ & 560 & 560 & 560 & 560 & 560 \\
\hline \multirow{3}{*}{$\begin{array}{l}\text { Le hacen } \\
\text { denigración }\end{array}$} & $\begin{array}{l}\text { Coeficiente de } \\
\text { correlación }\end{array}$ &,- 078 &,$- 110^{\star}$ &,- 034 &,- 054 &,- 031 \\
\hline & Sig. (bilateral) & ,122 & ,033 &, 509 & ,293 &, 550 \\
\hline & $\mathrm{N}$ & 560 & 560 & 560 & 560 & 560 \\
\hline \multirow{3}{*}{$\begin{array}{l}\text { Le hacen } \\
\text { revelación }\end{array}$} & $\begin{array}{l}\text { Coeficiente de } \\
\text { correlación }\end{array}$ &,- 054 &,- 047 &,- 045 &,- 008 &,- 038 \\
\hline & Sig. (bilateral) & ,291 &, 366 & ,390 & ,882 & ,466 \\
\hline & $\mathrm{N}$ & 560 & 560 & 560 & 560 & 560 \\
\hline \multirow{3}{*}{$\begin{array}{l}\text { Le hacen } \\
\text { suplantación }\end{array}$} & $\begin{array}{l}\text { Coeficiente de } \\
\text { correlación }\end{array}$ &,- 088 &,- 036 &,$- 103^{*}$ &, 061 &,$- 103^{*}$ \\
\hline & Sig. (bilateral) & ,087 & ,488 &, 049 & ,247 &, 049 \\
\hline & $\mathrm{N}$ & 560 & 560 & 560 & 560 & 560 \\
\hline \multirow{3}{*}{$\begin{array}{l}\text { Le hacen } \\
\text { exclusión }\end{array}$} & $\begin{array}{l}\text { Coeficiente de } \\
\text { correlación }\end{array}$ &,- 027 &,$- 1366^{* *}$ &,- 014 & ,046 & ,014 \\
\hline & Sig. (bilateral) & ,601 &, 010 & ,784 & ,379 & ,791 \\
\hline & $\mathrm{N}$ & 560 & 560 & 560 & 560 & 560 \\
\hline \multirow{3}{*}{$\begin{array}{l}\text { Le hacen } \\
\text { ciberacoso }\end{array}$} & $\begin{array}{l}\text { Coeficiente de } \\
\text { correlación }\end{array}$ & ,028 &,- 049 & ,080 &, 013 &, 002 \\
\hline & Sig. (bilateral) & ,572 & ,336 & ,110 & ,800 & ,973 \\
\hline & $\mathrm{N}$ & 560 & 560 & 560 & 560 & 560 \\
\hline \multirow{3}{*}{$\begin{array}{l}\text { Le hacen } \\
\text { Happy Slapping }\end{array}$} & $\begin{array}{l}\text { Coeficiente de } \\
\text { correlación }\end{array}$ &,- 052 &,- 046 & ,055 &,$- 116^{*}$ &,- 061 \\
\hline & Sig. (bilateral) & ,314 & ,378 & ,292 & ,027 & ,248 \\
\hline & $\mathrm{N}$ & 560 & 560 & 560 & 560 & 560 \\
\hline
\end{tabular}

En la Tabla 3, se observa que si bien no existe una correlación estadísticamente significativa entre la empatía en general y el ser víctima de ciberbullying, sin embargo, en consonancia con la hipótesis formulada en este estudio la Toma de perspectiva empática guarda correlaciones inversas y significativas tanto con el hecho de ser víctima de ciberbullying en general $(-, 108)$ como de ser víctima de 
Denigración $(-, 110)$ o de Exclusión $(-, 136)$. De otro lado, los componentes de la empatía de Malestar personal, Identificación con personajes y Preocupación empática muestran también correlación inversa y significativa con ser víctima de Happy Slapping $(-, 116)$ y ser víctima de Suplantación $(-, 103 ;-, 103)$, respectivamente. Concretamente a más competencia de un adolescente para la Toma de perspectiva empática, la Identificación con personajes o fantasear, la Preocupación empática o el Malestar personal, sería menos probable que sean víctimas de ciberbullying en general o bien en alguno de los tipos de ciberbullying mencionados. Resultados que sería interesante en estudios posteriores investigar más específicamente, puesto que estos análisis específicos habitualmente no se hacen en las investigaciones previas consultadas.

A manera de resultados complementarios, presentamos las Figuras 10 y 11, en las que se grafica el porcentaje de participación de los adolescentes de nuestro estudio en episodios de los distintos tipos de bullying medidos, en tanto víctimas o acosadores.

Como se puede observar en la Figura 10 hay una mayor predominancia de la participación en el rol de abusadores de los alumnos varones que de las niñas, en todos los tipos de ciberbullying evaluados, siendo esta diferencia aún mayor en los tipos realizar Insultos electrónicos o peleas online (un $13 \%$ de diferencia) y realizar Happy Slapping (un $22 \%$ de diferencia).

En la figura 11 se puede observar que existe una participación similar de ambos sexos en el rol de víctimas, a excepción de ser víctima de Happy Slapping (pero con una diferencia de apenas 6\%).

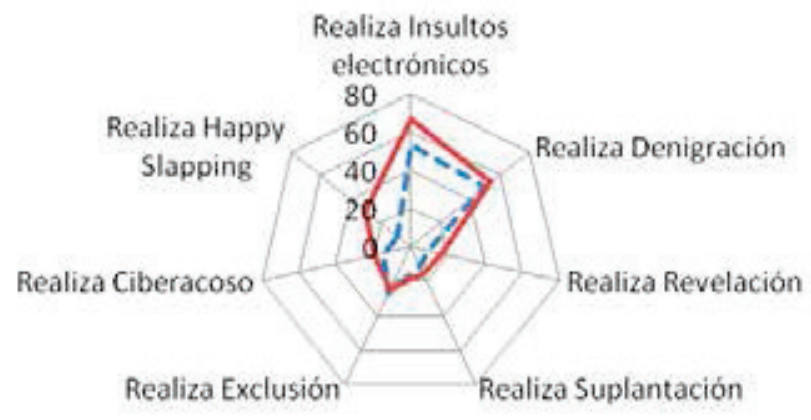

---Alumnas Alumnos

Figura 10. Porcentaje de alumnos que hacen los distintos tipos de ciberbullying en relación al sexo. 


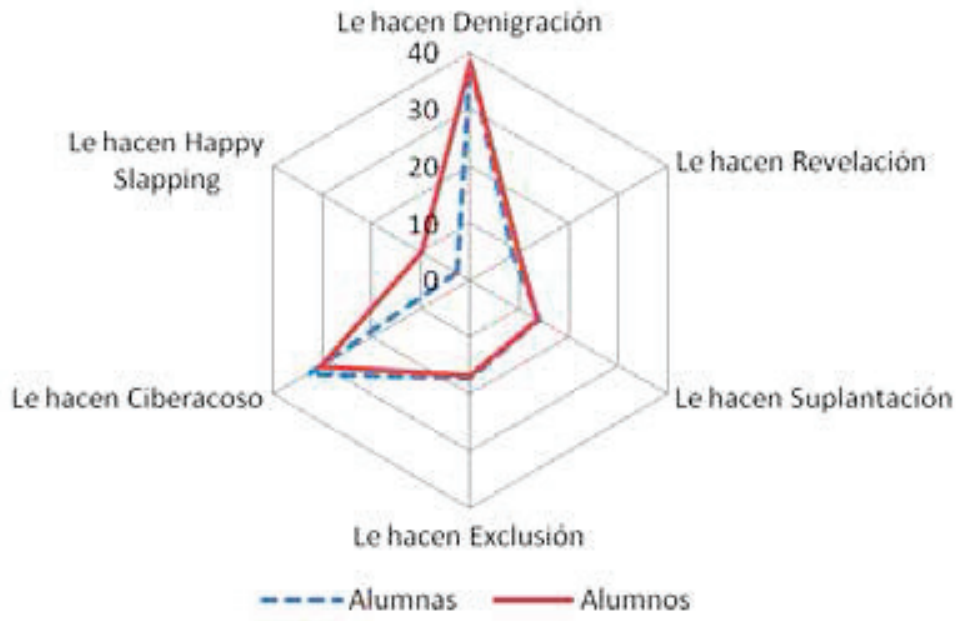

Figura 11. Porcentaje de alumnos víctimas de los distintos tipos de cyberbullying en relación al sexo

\section{CONCLUSIONES}

Del análisis de los resultados se puede concluir que:

1. Los adolescentes que perciben en sus padres un estilo de socialización parental, o de crianza, caracterizado porque sus progenitores se esfuerzan en dirigir sus actividades pero de una manera racional y orientada al proceso; estimulando el diálogo verbal y compartiendo con ellos el razonamiento que subyace a sus decisiones; valorando sus decisiones autónomas así como su conformidad disciplinada. Es decir, padres que si bien ejercen un control firme a sus comportamientos divergentes, sin embargo utilizan el diálogo para convencerlos de subordinarse. Son adolescentes que van a mostrar una capacidad para comprender al otro y ponerse en su lugar, a partir de lo que observan, de la información verbal o de la información recordada (toma de perspectiva) y la consecuente reacción afectiva de compartir el estado emocional de los otros, que les podría llevar a experimentar tristeza, malestar o ansiedad, inferior a la capacidad empática de los adolescentes que perciben en sus padres un estilo de socialización parental, o de crianza, Autoritario. Estilo de socialización parental caracterizado por su intento de modelar, controlar y evaluar la conducta y actitudes del adolescente de acuerdo con un conjunto de normas de conducta, normalmente de forma absoluta. Padres que valoran la obediencia como una virtud y favorecen medidas punitivas y de fuerza para doblegar la voluntad (la terquedad) cuando las acciones del adolescente o las creencias personales de este entran en conflicto con lo que ellos piensan que es una conducta correcta. Padres que valoran el respeto por la autoridad, respeto por el trabajo y respeto por la preservación del orden y de la estructura tradicional. Padres que no potencian el diálogo verbal, y creen que el hijo debería aceptar como ley su palabra pues, creen que es la única "absolutamente" correcta (Figura 9 y Tabla 1).

2. No existe una asociación directa entre las pautas de comportamiento de los padres con 
los hijos en múltiples y diferentes situaciones, ni las consecuencias que esos patrones de comunicación tienen para la propia relación paterno-filial, y la conducta agresiva e intencional que se repite de forma frecuente en el tiempo, que se lleva a cabo por uno o más adolescentes mediante el uso de medios electrónicos (las TIC, sea Internet: correo electrónico, weblogs, páginas personales etc; o sea la telefonía móvil), dirigida a una víctima que no puede defenderse por sí misma fácilmente. Posiblemente porque dado que en estos escenarios virtuales se podría decir que los padres son usualmente migrantes incipientes (García, F. 2010), el adolescente sería probablemente mas suceptible de ser influenciado por sus pares, de hecho más competentes en estos escenarios y en consecuencia modelos más adecuados para imitar (Bandura y Walters, 1978).

3. Los adolescentes que muestran una capacidad para comprender al otro y ponerse en su lugar, a partir de lo que observan, de la información verbal o de la información recordada (toma de perspectiva) y experimentan la consecuente reacción afectiva de compartir el estado emocional de los otros, que ocasionalmente les lleva a experimentar tristeza, malestar o ansiedad por el otro, no van a tender a presentar la conducta agresiva e intencional que se repite de forma frecuente en el tiempo, que se lleva a cabo por uno o mas adolescentes mediante el uso de medios electrónicos (las TIC, sea Internet: correo electrónico, weblogs, páginas personales etc.; o sea la telefonía móvil), dirigida a una víctima que no puede defenderse por sí misma fácilmente. Es decir, conforme aumenta su empatía disminuye su propensión a realizar ciberbullying en cualquiera de sus modalidades (Tabla 2).

4. Conforme los adolescentes presentan más competencia para adoptar la perspectiva 0 punto de vista de otras personas y mayor tendencia a experimentar sentimientos de compasión y preocupación hacia otros; o a experimentar sentimientos de incomodidad y ansiedad cuando son testigos de experiencias negativas de otros (Tabla 3). Es menos probable que sean víctimas de ciberbullying en general o de a) ser descalificados por la difusión de información despectiva y falsa respecto a su persona, la cual es colgada en una página web o difundida vía e-mail, mensajes instantáneos, b) ser infiltrados en su cuenta de correo para enviar mensajes que les hagan quedar mal, poniéndolos en situación problemática o en peligro, o dañando su reputación y amistades, c) ser grabados mediante la cámara de un teléfono móvil o fotografiados mientras son agredidos, en situación de minoría. Siendo esa imagen o video más tarde compartido con sus compañeros, colocado en algún espacio online o distribuido electrónicamente para ser humillado delante de miles de personas.

5. Del análisis complementario de los datos se puede concluir que, a desmedro de lo reportado por algunos estudios previos en el sentido que siendo el ciberbullying un tipo de violencia más relacional que física, se esperaría que las mujeres presenten una mayor prevalencia de este tipo de maltrato que los varones, se encuentra que hay una mayor predominancia de la participación en el rol de abusadores de los alumnos varones que de las niñas (Figura 10), como por ejemplo a enfrascarse en el intercambio mutuo de insultos breves y acalorados con otra persona con un lenguaje hostil y vulgar, mediante el Intercambio de e-mails privados o intercambio en contextos públicos como chats, o bien, grabando mediante una cámara de teléfono móvil imágenes en las que agreden a 
una persona en situación de minoría. Compartiendo más tarde la imagen o el vídeo con compañeros, colgándola en algún espacio online o distribuyéndola electrónicamente para que la vean miles de personas. Mientras que se presentan en ambos sexos similares porcentajes de ser victimizados mediante alguno de los tipos de ciberbullying medidos (Figura 11).

\section{REFERENCIAS BIBLIOGRÁFICAS}

Avilés, J. (2009). Cyberbullying. Boletín de Psicología, 96, 79-96. Recuperado de http:// dialnet.unirioja.es $/$ servlet/articulo? codigo $=3114500$

Bandura, A. y Walters, R.H (1978). Aprendizaje social y desarrollo de la personalidad. Madrid: Alianza.

Calvete, E., Orue, I. Estévez, A., ViIlardón, L., Padilla, P y, Sampedro (2009, Oslo). Cyberbullying in adolescents: Prevalence and associated risk factors. $11^{\text {th }}$ European Congress of Psychology.

Castells, M. (1999). Internet y la Sociedad red. Lección Inaugural del Programa de Doctorado sobre la Sociedad de la Información y el Conocimiento (UOC).

Davis, M.H. (1980). A multidimensional approach to individual differences in empathy. Catalog of Selected Documents in Psychology, 10 , 85,1-17.

Davis, M.H. (1983). Measuring individual differences in empathy: Evidence for a multidimensional approach. Journal of Personality and Social Psychology, 44, 113-126.

Garaigordobil, Maite (2011). Prevalencia y consecuencias del cyberbullying: una revisión. International Journal of Psychology and Psychological Therapy, 11, 2, pp. 233-254

García, F. (2010). Internet en la vida de nuestros hijos. España: Foro Generaciones Interactivas. Recuperado el 28/06/2013 de http://www.generacionesinteractivas.org/ upload/libros/Internet-en-la-vida-de-nuestros-hijos.pdf

García, L.; Orellana, M.; Pomalaya, R., Yanac, E:, Sotelo, L., Herrera, E. y cols. (2010). Cyberbullying en escolares de educación secundaria de Lima Metropolitana. Revista de la Facultad de Psicología, Vol. 13, nº 2, pp. 83-99.

Garaigordobil, M. (2011) Prevalencia y consecuencias del cyberbullying: una revisión. InternatIonal Journal of Psychology and PsychologIcal Therapy. 2011, 11, 2, pp. 233-254. Recuperado el 28/06/2013 de http://www.federicofroebel.org/secondary/ presentacion-redes/prevalencia-y-consecuencias-del-cyberbullying.pdf

Kowalski, R.M, Limber, S. P. \& Agatston, P.W. (2010). Cyber Bullying - El acoso escolar en la era digital. España: Desclée De Brouwer.

Mestre, V., Tur, A. M., Samper, P., Nácher, M.J. y Cortés, M.T. (2007). Estilos de socialización parental en la adolescencia y su relación con el comportamiento prosocial. Revista Latinoamericana de Psicología, Vol. 39, N. ${ }^{\circ} .2$, 2007 , pp. 211-225.

Musitu y García (2001). Escala de estilos de socialización parental en la adolescencia. ESPA 29. TEA Ediciones, 22. 
Oblitas B. (2009). Machismo y violencia contra la mujer. Investigaciones Sociales. Vol. 13 N. ${ }^{\circ} 23$, pp. 301-322 UNMSM.

Ortega R., Calmaestra J. y Mora Merchán J. A. (2007). Cuestionario de cyberbullying. Córdoba: Universidad de Córdoba.

Pérez-Albéniz, A., De Paúl, J., Etxeberría, J., Montes, M.P. y Torres, E. (2003). Adaptación de Interpersonal Reactivity Index (IRI) al español. Psicothema, 15(2), 267-272.

Quintana, A.; Montgomery, W. y Malaver, C. (2009). Modos de afrontamiento y conducta resiliente en adolescentes expectadores de violencia entre pares. Revista de la Facultad de Psicología UNMSM, Vol. 12, N. ${ }^{\circ}$ 1, pp. 153-172.

Quintana, A., Montgomery, W., Malaver, C; et al. (2010). Capacidad de disfrute y percepción del apoyo comunitario en adolescentes espectadores de episodios de violencia entre pares (bullying). Revista de la Facultad de Psicología UNMSM, Vol. 13 , N. ${ }^{\circ} 1$, pp. 139-150.

Richaud, M. C. (2008). Evaluación de la empatía en población infantil argentina. Revista de la Facultad de Psicología UNMSM. Vol. 11, N. ${ }^{\circ}$ 1, pp. 101-115.

Samper, P. (1999). Variables familiares y formación en valores. Tesis doctoral. Universidad de Valencia.

Samper, P; Cortés, M. T., Mestre, V., Nácher, M. J. y Tur, A. M. (2006). Adaptación del Child's Report of Parent Behavior Inventory a población española. Psicothema 2006. Vol. 18, N. ${ }^{\circ} 2$, pp. 263-271. Saddle River.

Smith, P.K., Mahdavi, J., Carvalho, C., y Tippett, N. (2006). An investigation into cyberbullying, its forms, awareness and impact, and the relationship between age and gender in cyberbullying. A Report to the Anti-Bullying Alliance. 
ESTILOS DE CRIANZA Y EMPATÍA EN ADOLESCENTES IMPLICADOS EN CIBERBULLYING

\title{
ANEXO 1. PRUEBA PARA EVALUAR CIBERBULLYING
}

\author{
CUESTIONARIO DE CB
}

Calvete, E., Orue, L., Estevez, A., Villardón, y Padilla, P. (2009)

Las siguientes frases se refieren al uso de internet y teléfonos móviles. Por favor responde con total sinceridad. Esta prueba es completamente anónima y confidencial. Indica con un aspa " $\mathrm{X}$ " en la celda que corresponda a la frecuencia con que has realizado alguna de las siguientes acciones:

\begin{tabular}{|c|c|c|}
\hline \multicolumn{3}{|c|}{ LO HE HECHO } \\
\hline Nunca & $\begin{array}{c}\text { Alguna } \\
\text { vez }\end{array}$ & $\begin{array}{c}\text { A } \\
\text { menudo }\end{array}$ \\
\hline
\end{tabular}

I. Mantener peleas y discusiones "online", empleando insultos, etc. por medio de mensajes electrónicos.

2. Enviar mensajes amenazantes o insultantes por e-mail

3. Enviar mensajes amenazantes o insultantes por teléfono celular 4. Colgar imágenes en internet de un(a) conocid@ ocompañer@que pueden ser humillantes (por ejemplo, de cuando se está vistiendo en el vestuario del gimnasio).

En caso afirmativo describe que tipo de imágenes

5. Enviar enlaces de imágenes humillantes a otras personas para que las puedan ver.

En caso afirmativo describe:

6. Escribir bromas, rumores, chismes o comentarios que ponían en ridículo a un compañer@en internet

7. Enviar enlaces donde aparecian rumores, chismes etc. de un(a) compañer@ o conocid@ a otras personas para que las leyeran.

8. Conseguir la contraseña (nicks, claves, etc.) de otra persona y enviar mensajes con su nombre por e-mail que le podían hacer quedar mal ante los demás o crearle problemas con conocidos.

9. Grabar video o tomar fotografias con el celular mientras un grupo se ríe y obliga a otra persona a hacer algo humillante o ridículo

En caso afirmativo describe:

10. Enviar esas imágenes a otras personas

11. Grabar video o tomar fotografías cuando alguien golpea o hace daño a otra persona

En caso afirmativo describe:

12. Enviar esas imágenes grabadas a otras personas

$\begin{array}{ccc}\text { N } & \text { AV } & \text { AM } \\ \text { N } & \text { AV } & \text { AM } \\ \text { N } & \text { AV } & \text { AM } \\ \text { N } & \text { AV } & \text { AM } \\ & & \\ & & \\ \text { N } & \text { AV } & \text { AM } \\ \text { N } & \text { AV } & \text { AM } \\ & & \\ & & \\ \text { N } & \text { AV } & \text { AM } \\ \text { N } & \text { AV } & \text { AM } \\ \text { N } & \text { AV } & \text { AM } \\ \text { N } & \text { AV } & \text { AM }\end{array}$

14. Apartar a alguien de modo intencional de un grupo online (chats, listas de amigos, foros temáticos, etc.).

15. Enviar insistentemente (de forma repetida) mensajes que incluyen amenazas o que son muy intimidatorios. 
16. Grabar video o tomar fotografias a algún(a) compañer@ con el celular en algún tipo de comportamiento de Índole sexual

17. Enviar esas imágenes a otras personas

$\begin{array}{lll}\text { N } & \text { AV } & \text { AM } \\ \text { N } & \text { AV } & \text { AM }\end{array}$

En las siguientes frases Indica con un aspa " $\mathrm{X}$ " en la celda que corresponda a la frecuencia con la que han realizado contigo alguna de las siguientes acciones:

\begin{tabular}{|c|c|c|}
\hline \multicolumn{2}{|c|}{ ME LO HAN HECHO A MI } \\
\hline Nunca & $\begin{array}{c}\text { Alguna } \\
\text { vez }\end{array}$ & $\begin{array}{c}\text { A } \\
\text { menudo }\end{array}$ \\
\hline
\end{tabular}

1. Enviarme mensajes amenazantes o insultantes por e-mail

2. Enviarme mensajes amenazantes o insultantes por teléfono celular

3. Colgar imágenes mías en internet que pueden ser humillantes (por ejemplo, vistiéndome en el vestuario del gimnasio).

En caso afirmativo describe que tipo de imágenes

$\begin{array}{ccc}\mathrm{N} & \text { AV } & \text { AM } \\ \mathrm{N} & \text { AV } & \text { AM } \\ \mathrm{N} & \text { AV } & \text { AM }\end{array}$

4. Escribir en internet bromas, rumores, chismes o comentarios que me ponían en ridículo

N AV AM

5. Conseguir mi contraseña (nicks, claves, etc.) y enviar mensajes en mi nombre por e-mail para dejarme mal ante los demás o crearme problemas con mis conocidos.

6. Grabarme en video o sacarme fotografías con el celular mientras un grupo se ríe y me obliga a hacer algo humillante o ridículo.

En caso afirmativo describe que tipo de imágenes

7. Grabarme en video o sacarme fotografías con el celular mientras alguien me golpea o me hace daño.

N AV AM

8. Difundir on line secretos, información comprometida o imágenes sobre mí

N AV AM

9. Apartarme de modo intencional de un grupo online (chats, listas de amigos, foros temáticos, etc.).

N AV AM

10. Enviarme mensajes insistentemente (de forma repetida) que incluyen amenazas o son muy intimidatorios.

N AV AM

11. Grabarme en video o sacarme fotografías con el celular en algún tipo de comportamiento de índole sexual

N AV AM 
ESTILOS DE CRIANZA Y EMPATÍA EN ADOLESCENTES IMPLICADOS EN CIBERBULLYING

\section{ANEXO 2. PRUEBA PARA EVALUAR LOS ESTILOS DE CRIANZA FAMILIAR}

\section{ESPA 29}

A continuación encontrarás una serie de situaciones que pueden tener lugar en tu familia. Estas situaciones se refieren a las formas en que tus padres responden cuando tú haces algo. Lee atentamente las situaciones y contesta, con la mayor sinceridad posible, señalando con un aspa $(\mathrm{X})$ la frecuencia con la que tu mamá hace cada una de ellas. No hay respuestas correctas

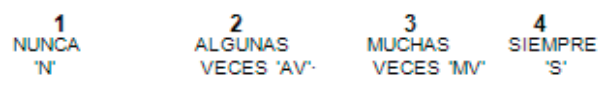

1. Si obedezco las cosas que me manda

2. Si no estudio o no quiero hacer las tareas que me mandan en el Colegio

3. Si viene alguien a visitarnos a casa y me porto con cortesía

4. Sí rompo o estropeo alguna cosa de mi casa

5. Si llevo a casa la libreta de notas con buenas calificaciones

6. Si estoy sucio y desaliñado

7. Si me porto adecuadamente en casa y no interrumpo sus actividades

8. Si se entera de que he roto o estropeado alguna cosa de otra persona, o en la calle

9. Si llevo a casa la libreta de notas con algún curso desaprobado

10. Si al llegar la noche, vuelvo a casa a la hora acordada, sin retraso

11. Si salgo de casa para ir a algún sitio, sin pedirle permiso a nadie

12. Si me quedo levantad@ hasta muy tarde, por ejemplo en la computadora

13. Si le informa alguno de mis profesores de que me porto mal en la clase
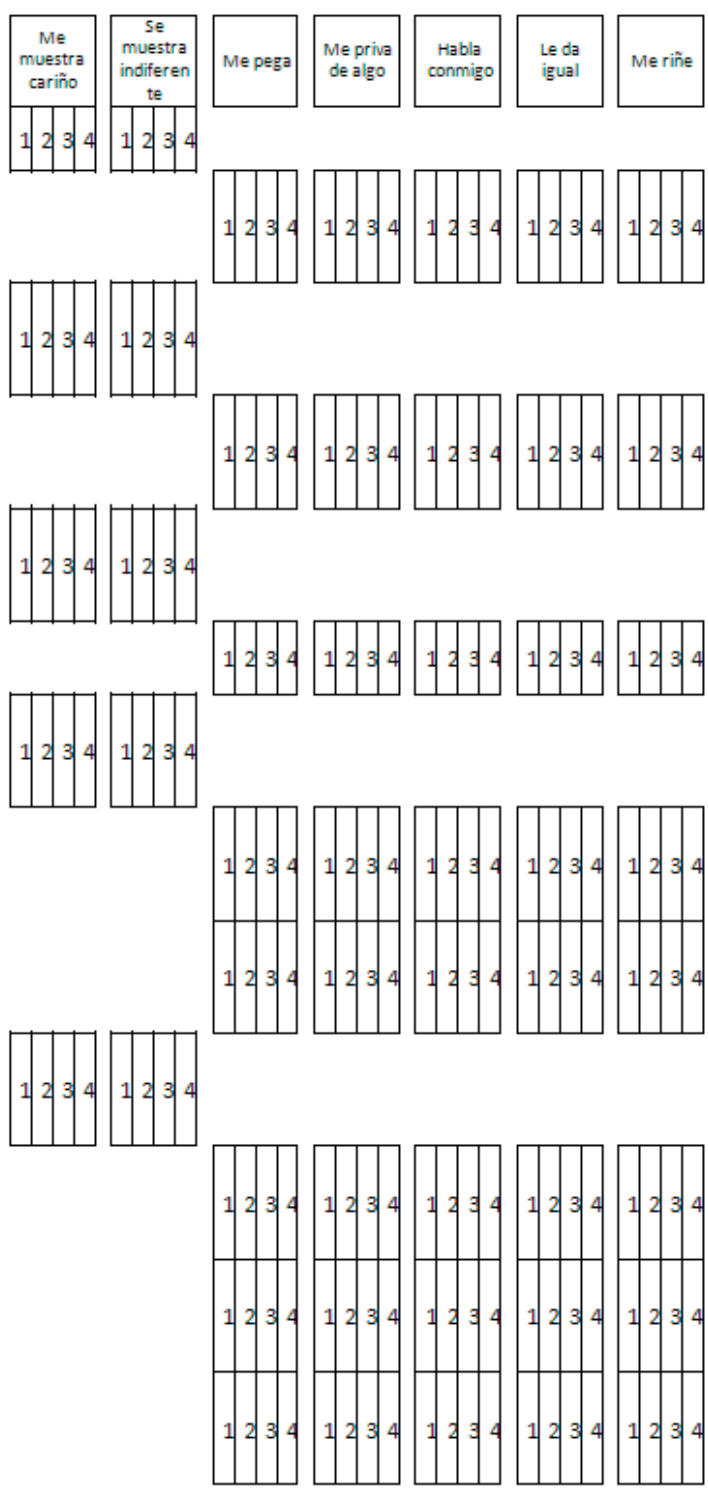
14. Si cuido mis cosas y voy limpi@ y asead@

15. Si digo una mentira y me descubren

16. Si respeto los horarios establecidos en mi casa

17. Si me quedo por ahí con mis amig@sy llego tarde a casa por la noche

18. Si ordeno y cuido las cosas en mí casa

19. Si me peleo con algún amig@o algun@ de mis vecin@s

20. Si me pongo furios@y pierdo el control por algo que me ha salido mal o por alguna cosa que no me ha dado

21. Cuando no como las cosas que me ponen en la mesa

22. Si mis amig@s o cualquier persona le comunican que soy buen(a) compañer@

23. Si habla con algun@ de mis profesores y recibe algún informe del colegio diciendo que me porto bien

24. Si estudio lo necesario y hago las tareas y trabajos que me mandan en clase 25. Si molesto en casa o no dejo que mis padres vean las noticias o el partido de fútbol

26. Si soy desobediente

27. Si como todo lo que me ponen en la mesa

28. Sí no falto nunca a clase y llego todos los días puntual

29. Si alguien viene a casa a visitarnos y hago ruido o molesto

En síntesis dirías que tu mamá:

30. Influencia en tu forma de ser \begin{tabular}{|c|c|c|c|c|} 
N & AV & MV & S \\
\hline 1 & 2 & 3 & 4 \\
\hline
\end{tabular}
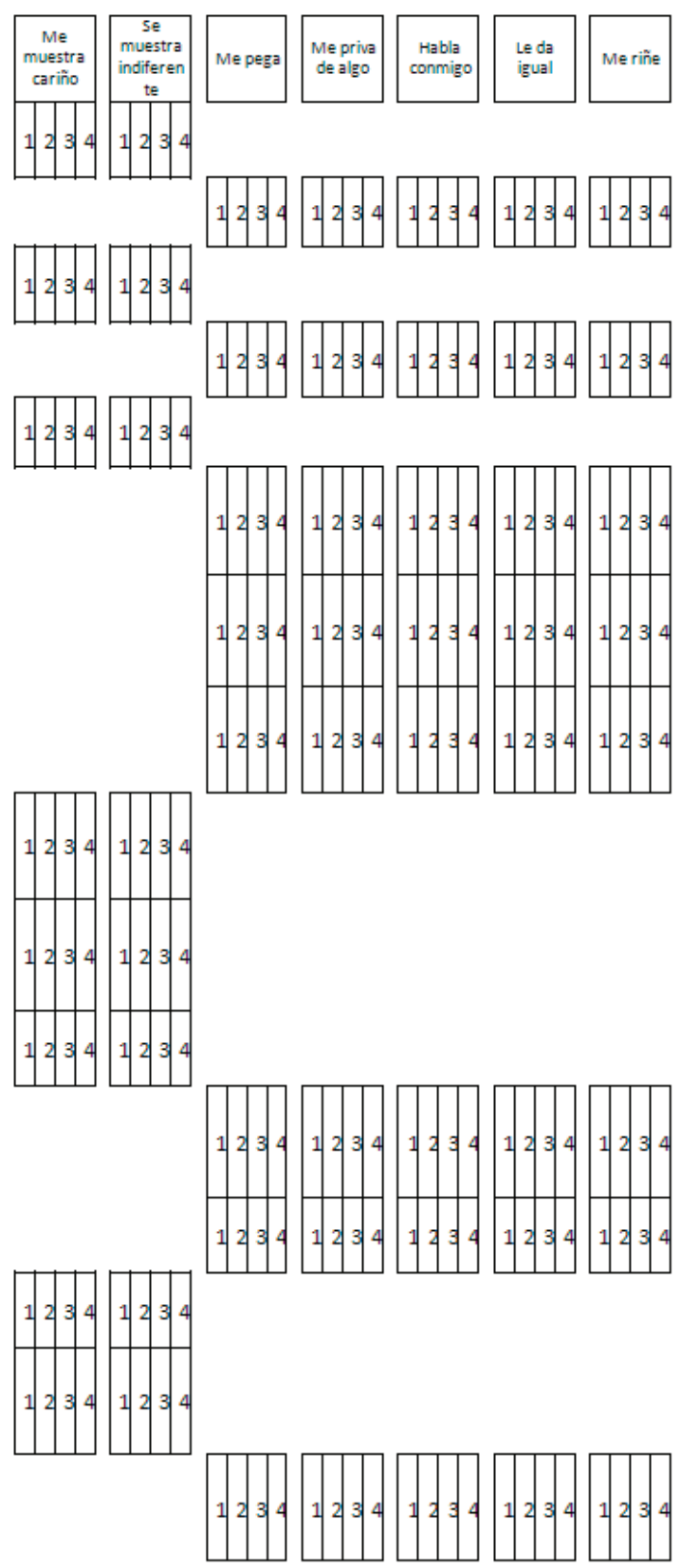

31. Por semana Interactúa contigo \begin{tabular}{|l|c|c|c|c|}
\hline $\mathrm{N}$ & $\mathrm{AV}$ & $\mathrm{MV}$ & $\mathrm{S}$ \\
\hline 1 & 2 & 3 & 4 \\
\hline
\end{tabular}

Análogo a este formato es la versión utilizada para la evaluación del estilo de socialización parental del padre. 
ESTILOS DE CRIANZA Y EMPATÍA EN ADOLESCENTES IMPLICADOS EN CIBERBULLYING

\section{ANEXO 3. PRUEBA PARA EVALUAR EMPATÍA}

\section{ÍNDICE DE REACTIVIDAD INTERPERSONAL}

(Davis, 1983)

Centro Educativo:

Distrito:

Turno: Sección: Sexo:

Edad:

Las siguientes afirmaciones se refieren a tus pensamientos y sentimientos en una variedad de situaciones. Para cada afirmación, tu deberás indicar lo bien que te describe eligiendo la letra correspondiente en la escala A, B, C, D ó E al lado de cada pregunta. Cuando hayas decidido tu respuesta, marca un aspa en la alternativa al lado de cada afirmación. Lee cada frase antes de responder. La evaluación es anónima, contesta lo más honestamente que puedas. Gracias.

$\begin{array}{rllll}\text { A } & \text { B } & \text { C } & \text { D } & \text { E } \\ \text { NO ME DESCRIBE } & & & & \text { ME DESCRIBE MUY BIEN }\end{array}$

\begin{tabular}{|c|c|c|c|c|c|}
\hline & & & & & \\
\hline $\begin{array}{l}\text { 1. Sueño, frecuentemente, acerca de las cosas que me podrían } \\
\text { suceder. }\end{array}$ & A & B & c & $\mathrm{D}$ & $\mathrm{E}$ \\
\hline 2. Me preocupa y conmueve la gente con menos suerte que yo. & A & B & $\mathrm{c}$ & $\mathrm{D}$ & $\mathrm{E}$ \\
\hline $\begin{array}{l}\text { 3. Encuentro difícil ver las cosas desde el punto de vista de otra } \\
\text { persona. }\end{array}$ & A & B & $\mathrm{C}$ & $\mathrm{D}$ & $\mathrm{E}$ \\
\hline 4. No me preocupan los problemas de los demás. & A & B & $\mathrm{C}$ & $\mathrm{D}$ & $\mathrm{E}$ \\
\hline 5. Me identifico con los personajes de una novela. & A & B & $\mathrm{C}$ & $\mathrm{D}$ & $\mathrm{E}$ \\
\hline 6. En situaciones de riesgo, tengo miedo. & A & B & C & $\mathrm{D}$ & $\mathrm{E}$ \\
\hline 7. No me compenetro con los personajes de película u obras de teatro. & A & B & C & $\mathrm{D}$ & $\mathrm{E}$ \\
\hline 8. Escucho diferentes opiniones cuando tengo que decidir algo. & A & B & C & D & $\mathrm{E}$ \\
\hline 9. Tiendo a proteger a aquell@s que I@s agarran de punto. & A & B & $\mathrm{C}$ & $\mathrm{D}$ & $\mathrm{E}$ \\
\hline $\begin{array}{l}\text { 10. Me siento vulnerable (no sé qué hacer) frente a una situación muy } \\
\text { emotiva. }\end{array}$ & A & B & $\mathrm{C}$ & $\mathrm{D}$ & $\mathrm{E}$ \\
\hline $\begin{array}{l}\text { 11. Intento comprender mejor a mis amig@s imaginándome cómo ven } \\
\text { ell@s las cosas. }\end{array}$ & A & B & C & $\mathrm{D}$ & $\mathrm{E}$ \\
\hline 12. Me es difícil entusiasmarme con un buen libro o película. & A & B & $\mathrm{C}$ & $D$ & $\mathrm{E}$ \\
\hline 13. Cuando veo a alguien herido, no me asusto. & A & B & $\mathrm{c}$ & $\mathrm{D}$ & $\mathrm{E}$ \\
\hline 14. Las desgracias (dolor) de otros no me molestan & A & B & $\mathrm{c}$ & D & $\mathrm{E}$ \\
\hline
\end{tabular}


15. Si estoy segur@ que tengo la razón en algo, no pierdo tiempo escuchando los argumentos de los demás.

16. Después de ver una obra de teatro o cine me he sentido como si fueraun@de los personajes.

17. Cuando estoy en una situación emocionalmente tensa, me asusto.

18. Cuando veo que otr@ chic@está siendo tratad@ injustamente, no siento ninguna compasión por él/ella.

19. Normalmente soy bastante eficaz (sé qué hacer) en situaciones difíciles

20. Me altero por las cosas que veo que ocurren alrededor.

21. Pienso que hay dos partes (diferentes puntos de vista) para cada situación, e intento tenerlas en cuenta,

22. Me describiría como una persona bastante sensible,

23. Cuando veo una buena película puedo muy fácilmente ponerme en el lugar del(a) protagonista.

24. Tiendo a perder el control frente a situaciones difíciles.

25. Cuando estoy disgustad@ con alguien, intento ponerme en su lugar por un momento o

26. Cuando estoy leyendo una historia interesante o una novela, imagino cómo me sentiría si los acontecimientos de la historia me sucedieran a mí.

27. Cuando veo a alguien que necesita urgentemente ayuda en una emergencia no sé qué hacer.

28. Antes de criticar a alguien, intento imaginar cómo me sentiría si estuviera en su lugar.

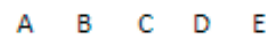

A B C D E

A B C D E

A B C D E

A $B \quad C \quad D \quad E$

A $B$ C $\quad$ D $\quad E$

A B C D E

A $\quad B \quad C \quad D \quad E$

A B C D E

A B C D E

A B C D E

A $\quad B \quad C \quad D \quad E$

A B C D E

A B C D E 